\title{
Avian Growth Depression in Chickens Induced by Environmen- tal, Microbiological, or Nutritional Stress Is Moderated by Probiotic Administrations of Lactobacillus reuteri
}

\author{
Holly J. Dunham, ${ }^{1}$ Ivan A. Casas, ${ }^{3}$ Frank W. Edens, ${ }^{2}$ Carmen R. Parkhurst, ${ }^{2}$ \\ Jim D. Garlich ${ }^{2}$ and Walter J. Dobrogosz' \\ 'Department of Microbiology and '2Department of Poultry Science, North Carolina State University, Raleigh, North Carolina, 27695 \\ USA \\ ${ }^{3}$ BioGaia Biologics, Inc., Raleigh, North Carolina, 27613 USA
}

Received July 17, 1998; Accepted for publication, August 20, 1998

\begin{abstract}
Avian growth depression (AGD) has been cited as the costliest disease affecting the poultry industry. It occurs when young chickens or turkeys are exposed to nutritional, environmental, and/or microbiological stressors. In this report we describe model systems developed to study AGD in chickens under controlled laboratory conditions. Mild intermittent cooling during the first $48 \mathrm{hr}$ posthatch, peroral Salmonella challenges during the first few days posthatch, and feeding newly-hatched chicks a protein deficient diet were shown to induce AGD. We had previously shown that AGD induced by intermittant cooling of newly hatched poults could be moderated by probiotic administrations of Lactobacillus reuteri. In the present report, evidence is presented showing that moderation of this disease by $L$. reuteri treatments occurs in chickens as well, and that this probiotic protection occurs whether the disease is induced by an environmental, microbiological, or nutritional stressor.
\end{abstract}

Key words: Lactobacillus reuteri; probiotics; chickens; growth depression

\section{INTRODUCTION}

The research presented in this report describes a newly discovered relationship between avian growth depression (AGD) and presence of $L$. reuteri in the chicken gastrointestinal (GI) tract. This relationship, first described in turkeys (6), was found to exist in chickens as well.

The term "poult growth depression" (PGD) was introduced by Barnes $(2,3)$ to describe the suboptimal growth and overall performance losses resulting from what has been calculated the most costly "disease" affecting the turkey industry. PGD was shown to commence soon after hatch and to persist to market age. Uncommon or mild on new farms or in first flocks returned to depopulated farms, PGD is most common and often severe on farms in continuous production $(2,3)$. Decreased livability is also associated with this syndrome, but its relationship to other diseases causing poor growth is unknown. Mortality occurs during the first week posthatch in direct relation to the intensity with which flocks are exposed to microbiological and environmental stressors. Inasmuch as this 'disease' appears to occur in chickens as well as turkeys $(9,17,25,26)$, we have proposed a more generic designation for this syndrome, namely avian growth depression (AGD).

L. reuteri is a major component of the Lactobacillus population indigenous to the gastrointestinal (GI) tract of humans and animals, including chickens and turkeys $(5,11,19,27,31,32)$. It is the only lactobacilli known to produce and secrete 3-hydroxypropionaldehyde (reuterin) $(1,8,36-39)$. Mammals are inoculated with L. reuteri by their mothers during nursing. It has been shown in pigs, for example, that the sow's nipples and milk are rich sources of $L$. reuteri, and that colonization of the GI tract by this intestinal lactobacilli occurs shortly after nursing (11). This route of inoculation is obviously precluded in avian species, where it is replaced presumably by coprophagy of adult cecal and fecal droppings that serve as inocula for the newly hatched birds. In commercial production, however, chickens and turkeys are deprived of these sources because they are hatched and brooded in the absence of adults. Thus, flocks hatched and brooded under commercial conditions are only sparsely colonized by $L$. reuteri (5).

In this report, we subjected newly-hatched chicks to AGD induced by low dietary protein, mild cold stress, and/or Salmonella typhimurium challenge. We hypothesized that AGD-associated performance losses incurred under these conditions could be moderated by probiotic treatments with viable, host-specific $L$. reuteri as had been shown in previous studies with poults (6). 


\section{MATERIALS AND METHODS}

Chickens used and general brooding conditions. All experiments were conducted under the guidelines of the Institution Animal Care and Use Committee. At the end of each experiment or when tissues were to be taken, the animals were killed with $\mathrm{CO}_{2}$ asphyxiation. Mixedsex or all male Arbor Acres $\times$ Arbor Acres broiler chicks obtained within $6 \mathrm{hr}$ post-hatch were placed in the NC State University Dearstyne Poultry Science Laboratory animal care rooms in custom-designed floor brooders or Petersime chick brooding batteries. As appropriate, the floor brooders and Petersime brooders were equipped with heaters, pen dividers, and deck lights. Feed, water, and light were provided continuously for a 21 day experimental period. The birds consumed ad libitum a standard broiler starter diet in mash form mixed at the North Carolina Agricultural Research Service poultry research unit. No antibiotics were included in the diets.

Experimental conditions for normal and stressorassociated brooding. Normal-brooded control chicks were placed in battery pens in which the temperatures were maintained held at $32^{\circ} \mathrm{C}$ for 8 days, at $29^{\circ} \mathrm{C}$ for the next 6 days, and then at $27^{\circ} \mathrm{C}$ until 21 days. Coldstress brooded chicks were placed in batteries in which the pen heaters were off for the first hour after placement to assure an ambient temperature of $18^{\circ} \mathrm{C}$, and the heaters were then turned on for $2 \mathrm{hr}$ for the temperature to reach $32^{\circ} \mathrm{C}$. This cycle was repeated continuously for the first 2 days with normal brooding resumed thereafter. Cold-stressed, Salmonella-challenged brooded chicks were subjected to the same cold stress regimen, but they were administered $10^{6} \mathrm{cfu} S$. typhimurium by gavage into the crop at the time of placement into the brooders. The inocula for oral gavage were grown overnight $\left(37^{\circ} \mathrm{C}\right)$ in Trypticase Soy Broth (Difco) as previously described (41). Proteinstressed brooded chicks were brooded at optimal temperature but fed a diet containing $16.1 \%$ protein instead of the optimal $19.9 \%$ protein. Diets supplemented with bacitracin and/or monensin were included in these experiments. $L$. reuteri-treated birds in every experiment were identical to the corresponding control chicks except that the newly hatched chicks were sprayed topically with $L$. reuteri, and their feed was supplemented with $2.0 \%$ whey pellets coated with viable $L$. reuteri (chick strain 11284) to yield a final concentration of $5 \times 10^{5} \mathrm{cfu} / \mathrm{g}$ feed as described elsewhere (2). Preliminary studies showed that addition of a whey pellet placebo was ineffective in preventing stress-associated growth depression. Each experimental group generally consisted of 6 pens with 16 birds per pen. Mortalities were monitored daily, and 60 birds from each treatment group were selected at random for body weight determinations generally at $0,7,14$ and 21 days posthatch.

Enumeration of S. typhimurium and L. reuteri in ceca. The cecum was selected as the target organ for analyzing presence of $L$. reuteri and $S$. typhimurium in the gut. S. typhimurium ST-10 $\left(\mathrm{Nov}^{\mathrm{r}}, \mathrm{Nal}^{\mathrm{r}}\right)$, obtained through the courtesy of Dr. D. E. Corrier (USDA ARS, College Station, Texas, USA), was isolated from poultry and is resistant to both Novobiocin $(25 \mu \mathrm{g} / \mathrm{ml})$ and Naladixic acid $(20 \mu \mathrm{g} / \mathrm{ml})$. It is an effective pathogen for newly hatched chicks and readily enumerated as described elsewhere using agar media containing the above antibiotics at the indicated concentrations (41). Cecal contents were diluted and homogenized 1:10 in $0.05 \mathrm{M}$ phosphate buffer ( $\mathrm{pH} 7.0)$ and plated on this selective medium. Total lactobacilli in the cecal preparations were enumerated on Lactobacillus Selection Medium (Difco), and the sub-population of L. reuteri cells determined as those colonies able to produce reuterin as described elsewhere (11). Total enterobacteria were enumerated using Difco MacConkey's agar.

Probiotic treatments with L. reuteri. Commercial preparations of $L$. reuteri were used as previously described (5). Newly hatched chicks were sprayed with GAIAspray ${ }^{\circledR}$ during placement and GAIAfeed ${ }^{\circledR}$ was included in the diet for the 21 day experimental period. These delivery systems were prepared and used as follows: GAIAspray ${ }^{\circledast}$ contained viable, lyophilized (Rhone-Poulanc, Inc.) L. reuteri (chicken-specific strain 11284 ) cells suspended at a concentration of $10^{8} \mathrm{cfu} /$ $\mathrm{ml}$ and sprayed onto the chicks during placement. GAIAfeed ${ }^{\circledR}$ contained the same lyophilized preparations of $L$. reuteri but coated onto compressed whey particles which were admixed with the feed to give a final viable cell concentration of $5.0 \times 10^{5}$ to $1.0 \times 10^{6} \mathrm{cfu} L$. reuteri $/ \mathrm{g}$ of feed. As was established previously for poults (5), microbiological examination of cecal contents showed that essentially all chicks treated with these $L$. reuteri preparations were colonized with this microorganism. Only approximately $10 \%$ of untreated chicks had detectable $L$. reuteri in their ceca at the time of hatching and placement in brooder pens. Untreated birds served as the comparative controls in all experiments.

Statistical analyses. The data for body weights, mortality, and cecal bacterial counts were subjected to analysis of variance using the general linear models procedure of the Statistical Analysis System $\left(\mathrm{SAS}^{\circledR} \mathrm{In}\right.$ - 
Table 1. Effect of Lactobacillus reuteri on body weight gain in broilers fed a protein-deficient diet

\begin{tabular}{clcc}
\hline Diet & \multicolumn{1}{c}{ Treatments } & Wt. gain $(\mathrm{g})$ & \% increase \\
\hline \multirow{2}{*}{$19.9 \%$ protein } & Control & $601^{\mathrm{a}}$ & - \\
& + Mon., Bact. & $609^{\mathrm{a}}$ & 1.3 \\
& + Mon., Bact., Lr & $609^{\mathrm{a}}$ & 1.3 \\
& $+\mathrm{Lr}$ & $609^{\mathrm{a}}$ & 1.3 \\
\multirow{3}{*}{$16.1 \%$ protein } & Control & $530^{\mathrm{c}}$ & - \\
& + Mon., Bact. & $549^{\mathrm{bc}}$ & 3.5 \\
& $+\mathrm{Lr}$ & $553^{\mathrm{b}}$ & 4.3 \\
\hline
\end{tabular}

a.b.c Unlike superscripts indicate significant $(p \leq 0.05)$ differences from control; Bact. = bacitracin added at $1 \mathrm{lb}$. per ton feed; Mon. = monensin added at $4.5 \mathrm{lbs}$. per ton feed; $\mathrm{Lr}=L$. reuteri added at $5 \times 10^{5} \mathrm{cfu} / \mathrm{g}$ feed.

Table 2. Effect of Lactobacillus reuteri on growth and livability of 21 day-old chicks exposed to intermittant mild cold and/or Salmonella challenge

\begin{tabular}{|c|c|c|c|c|c|}
\hline $\begin{array}{l}\text { Exp. } \\
\text { No. }\end{array}$ & Conditions & $\begin{array}{l}\text { Body wt. } \\
\text { (g) }\end{array}$ & $\begin{array}{c}\text { Wt. change } \\
(\%)\end{array}$ & $p$ & $\begin{array}{l}\text { Mort. } \\
(\%)\end{array}$ \\
\hline \multirow[t]{4}{*}{1} & NB-C & 758 & & & 0 \\
\hline & NB-Lr & 781 & +3.0 & 0.22 & 1 \\
\hline & SB-C $21 \mathrm{C}$ & 749 & & & $0^{\mathrm{a}}$ \\
\hline & SB-Lr $21 \mathrm{C}$ & 767 & +2.4 & 0.29 & $0^{\mathrm{a}}$ \\
\hline \multirow[t]{2}{*}{2} & SB-C $23 \mathrm{C}+\mathrm{St}\left(10^{5} \mathrm{cfu}\right)$ & 735 & & & $0^{\mathrm{a}}$ \\
\hline & SB-Lr $23 \mathrm{C}+\mathrm{St}\left(10^{5} \mathrm{cfu}\right)$ & 771 & +4.9 & 0.01 & $0^{\mathrm{a}}$ \\
\hline \multirow[t]{2}{*}{3} & \multirow{2}{*}{$\begin{array}{l}\text { SB-C } 18 \mathrm{C}+\mathrm{St}\left(10^{4} \mathrm{cfu}\right) \\
\text { SB-Lr } 18 \mathrm{C}+\mathrm{St}\left(10^{4} \mathrm{cfu}\right)\end{array}$} & 640 & & & $28^{\mathrm{a}}$ \\
\hline & & 700 & +9.4 & 0.02 & $6^{\mathrm{b}}$ \\
\hline \multirow[t]{2}{*}{4} & \multirow{2}{*}{$\begin{array}{l}\text { SB-C } 18 \mathrm{C}+\mathrm{St}\left(10^{6} \mathrm{cfu}\right) \\
\text { SB-Lr } 18 \mathrm{C}+\mathrm{St}\left(10^{6} \mathrm{cfu}\right)\end{array}$} & 750 & & & $4^{a}$ \\
\hline & & 769 & +2.5 & 0.19 & $4^{\mathrm{a}}$ \\
\hline \multirow[t]{4}{*}{5} & NB-C & 751 & & & $0^{\mathrm{a}}$ \\
\hline & NB-Lr & 769 & +2.4 & 0.13 & $0^{\mathrm{a}}$ \\
\hline & SB-C $18 \mathrm{C}+\mathrm{St}\left(10^{6} \mathrm{cfu}\right)$ & 733 & & & $21^{\mathrm{a}}$ \\
\hline & SB-Lr $18 \mathrm{C}+\mathrm{St}\left(10^{6} \mathrm{cfu}\right)$ & 772 & +5.3 & 0.01 & $11^{\mathrm{b}}$ \\
\hline \multirow[t]{4}{*}{6} & SB-C $18 \mathrm{C}$ & 565 & & & $40^{\mathrm{a}}$ \\
\hline & SB-Lr $18 \mathrm{C}$ & 609 & +7.8 & 0.02 & $25^{\mathrm{b}}$ \\
\hline & $\mathrm{SB}-\mathrm{C} \quad+\mathrm{St}\left(10^{7} \mathrm{cfu}\right)$ & 542 & & & $3^{a}$ \\
\hline & $+\mathrm{St}\left(10^{7} \mathrm{cfu}\right)$ & 644 & +18.8 & 0.01 & $1^{\mathrm{a}}$ \\
\hline
\end{tabular}

Column 1: Experiment number. Column 2: NB = normal brooding conditions; $\mathrm{SB}=$ stressed brooding conditions with indicated stressor(s); $\mathrm{C}=$ controls; $\mathrm{Lr}=$ L. reuteri-treated; $\mathrm{St}=S$. typhimurium-challenged with indicated CFU per bird. Column 3: Body wt. $(\mathrm{g})=$ body weight in grams at 21 days of age. Column 4: Wt. change $(\%)=\%$ change in body weight caused by the $L$. reuteri treatment compared to corresponding control birds. Column 5: $p=p$ value for body weight difference. Column 6: Mort. $(\%)=$ $\%$ cumulative flock mortality at 21 days of age with unlike $(a, b)$ superscripts indicating a significant $(p \leq 0.05)$ difference from the respective control.

stitute, 1994. A User's Guide to the Statistical Analysis System. SAS ${ }^{\circledR}$ Institute, Cary, North Carolina, USA). Percentage data for mortality and percentage carcass grades were converted to angles (arcsin) and analyzed by analysis of variance. Differences between treatment means were determined by Student's $t$-test. Statements of significance were based upon $p \leq 0.05$.

\section{RESULTS}

Comparative Effects of L. reuteri and Antimicrobial Agents on Growth of Protein-Stressed Chicks

The experiment shown in Table 1 consisted of a control group of chicks fed for 21 days a normal diet containing $19.9 \%$ protein, and another 'protein-stressed' 
group fed a diet containing only $16.1 \%$ protein. It can be seen that neither $L$. reuteri nor the antimicrobial regimen of monensin and bacitracin had any effect on the 21 day body weight gain of the unstressed chicks. Growth of the protein-deficient chicks, on the other hand, was clearly depressed, but it can be seen that the probiotic and antimicrobial regimens significantly moderated this growth depression. It was also shown that L. reuteri probiosis was as effective in moderating this growth depression as was the combination of bacitracin and monensin.

Effect of L. reuteri on Growth and Livability of Chicks Exposed to Environmental and Microbiological Stressors

Although chickens are considerably more resistant to cold stress than turkeys, we found them generally as susceptible to stressor-associated AGD. The six experiments summarized in Table 2 are representative of experiments in which AGD was induced in young chickens by application of single or combined stressors in the form of mild cold stress and/or Salmonella challenge. Birds brooded under normal/optimal conditions (NB) were included in some these experiments for direct comparison to birds brooded under stressed conditions (SB). In Experiment 1 no significant effect on either livability or growth was observed when the birds were brooded normally or when subjected to a very mild intermittent cold stress. Although $L$. reuteri stimulated growth slightly in both cases, the effect had only near significance at best. The results obtained from Experiment 2 showed that the $L$. reuteri treatment significantly moderated AGD in chicks that were subjected to mild cold stress concomitant with Salmonella challenge. The overall mortality rate in this experiment was negligible. In Experiment 3, not only was the AGD induced by the indicated stressor combination significantly moderated by the $L$. reuteri treatment, as indicated by a $9.4 \%$ greater body weights, but a dramatic reduction in flock death rate from $28 \%$ to $6 \%$ was also observed. Figure 1 shows the data obtained when the results from Experiment 3 were plotted as a function of time. It can be seen that the stressor-induced deaths occurred between 3 and 6 days posthatch, and the stimulatory effect of $L$. reuteri on body weight growth became evident by the end of the first week posthatch. Often, an L. reuteri-induced acceleration of feathering was observed at this time as well. This is deemed an important observation in that with increased feathering there is a decreased heat loss and thereby an improved conversion of feed into body weight.
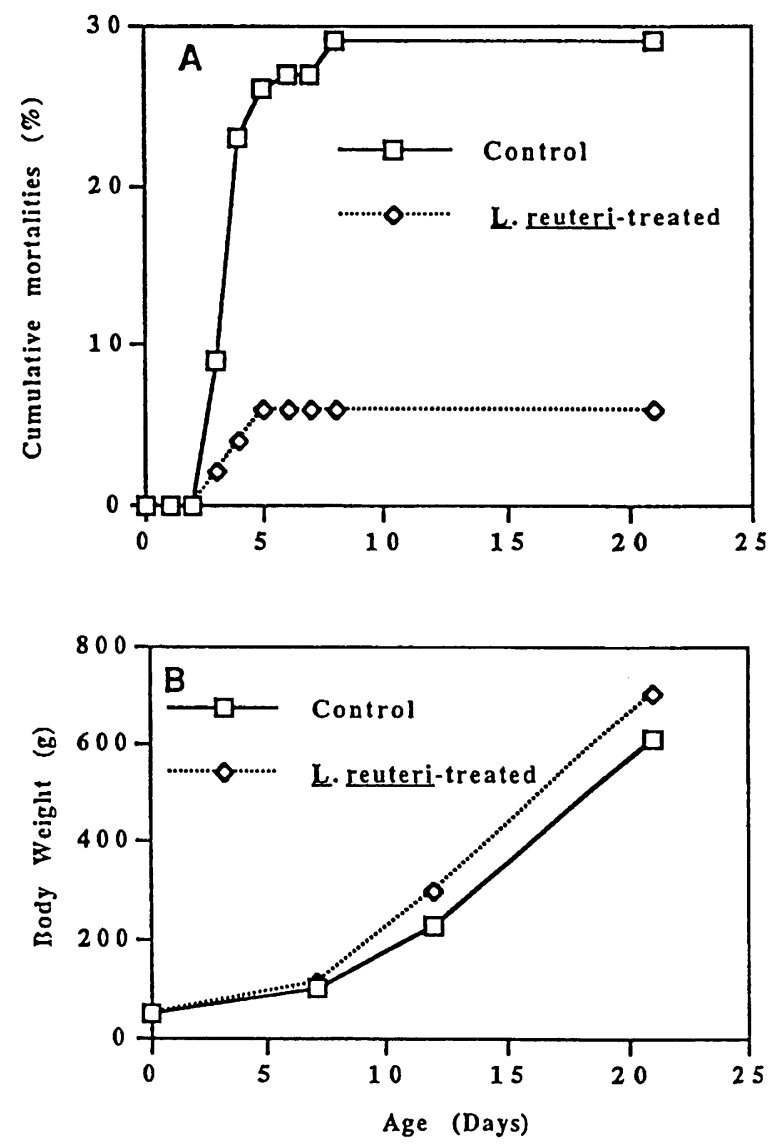

Fig. 1. Effect of Lactobacillus reuteri treatment on growth and livability of chickens exposed to combined microbiological (Salmonella typhimurium) and environmental (cold) stressors. Graph A: Effects on livability during 21 days posthatch. Graph B: Effects on growth during 21 days posthatch.

By using randomized groups of birds divided into control and treated sub-groups and by applying stressors in a controlled manner, we were able to evaluate the probiotic effectiveness of $L$. reuteri with reasonable accuracy. This is not to say that we were able to completely avoid the 'variability factor' so often encountered in the study of probiotics (16). This factor can be seen, for example, by comparing the results obtained in Experiments 3 and 4. The same temperature stress was applied in both experiments, and the birds in Experiment 4 were administered a 100 times larger Salmonella challenge. Yet, the control birds in Experiment 3 were clearly more susceptible to these stressors. They weighed approximately $100 \mathrm{~g}$ less than expected at day 21 , and they exhibited a much higher death rate than did the control birds in Experiment 4. Furthermore, it can be seen that $L$. reuteri was considerably more effective in moderating AGD in the more stress-susceptible group. Another example of inherent 
Table 3. Effect of Lactobacillus reuteri treatment on total enterobacterial and Salmonella typhimurium counts in chicken ceca during the first 3 weeks posthatch

\begin{tabular}{cllcccccc}
\hline \multirow{2}{*}{$\begin{array}{c}\text { Bacteria } \\
\text { enumerated }\end{array}$} & & \multicolumn{7}{c}{$\log _{10}$ CFU/g cecal contents on day: } \\
\cline { 3 - 9 } & & 1 & 3 & 4 & 5 & 7 & 14 & 21 \\
\hline Enterobacteria & Controls & $10.0^{\mathrm{a}}$ & $10.4^{\mathrm{a}}$ & $10.4^{\mathrm{a}}$ & $9.2^{\mathrm{a}}$ & $\mathrm{ND}$ & $\mathrm{ND}$ & ND \\
& L. reuteri & $10.3^{\mathrm{a}}$ & $9.9^{\mathrm{a}}$ & $9.5^{\mathrm{a}}$ & $8.8^{\mathrm{a}}$ & ND & ND & ND \\
S. typhimurium & Controls & $\mathrm{ND}$ & $6.2^{\mathrm{a}}$ & ND & ND & $6.1^{\mathrm{a}}$ & $4.6^{\mathrm{a}}$ & $4.2^{\mathrm{a}}$ \\
& L. reuteri & ND & $6.0^{\mathrm{a}}$ & ND & ND & $6.0^{\mathrm{a}}$ & $2.8^{\mathrm{b}}$ & $2.1^{\mathrm{b}}$ \\
\hline
\end{tabular}

All chicks were stress-brooded (intermittent $18^{\circ} \mathrm{C}$ plus $10^{4} \mathrm{cfu} S$. typhimurium per bird). ND=not determined; ${ }^{a \cdot b}$ numbers with unlike superscripts indicates a significant difference from the control $(p \leq 0.05)$.

biological variability can be seen by comparing the results obtained in Experiments 4 and 5. Identical stressors were applied in both experiments, but their toll was greater on the birds used in Experiment 5. In this experiment, growth was more depressed, the mortality rate was higher, and $L$. reuteri's ability to moderate these performance losses was clearly more evident.

Experiment 6 summarizes results obtained from an experiment in which the temperature and microbialchallenge stressors were applied individually. It can be seen that: (a) each stressor caused a severe growth depression (when compared to unstressed birds as shown in Experiments 1 and 5), (b) cold stress induced a high mortality in addition to growth depression, and (c) $L$. reuteri probiosis significantly moderated these performance losses in both cases.

\section{Effect of L. reuteri on the Cecal Content of Enterobac- teria and $S$. typhimurium}

A microbiological examination of the effect of $L$. reuteri treatment on the number of enterobacteria and $S$. typhimurium present in the ceca is summarized in Table 3. Although $L$. reuteri treatment had a significant competitive exclusion (CE) effect on the cecal $S$. typhimurium counts during the second and third weeks posthatch, there seemed to be little or no CE of either $S$. typhimurium or enterobacteria during the first week, the period when $L$. reuteri manifested its protective effects on AGD. Thus, while $L$. reuteri colonization of the avian gut can promote a significant $\mathrm{CE}$ effect, this effect alone may not account for this probiotic's ability to moderate AGD. In this connection, preliminary studies suggest that $L$. reuteri colonization of the gut may potentiate the avian immune response (13).

\section{DISCUSSION}

As early as 1878, Pasteur demonstrated the deleterious effects of combined stressors, namely, cold stress and pathogen challenge, on growth and mortality in chickens (24). Since then it has been shown that these and other stressors cause what physiologists call an 'alarm reaction' that retards an animals growth or can initiate an actual weight loss $(4,10,14,20-22,28,30$, $33,40-42)$. Newly hatched chicks are particularly sensitive to these stressors, and growth retardation and tissue damage incurred early in life can persist into adulthood (12).

Barnes $(2,3)$ has suggested that these stressor-associated losses in the turkey industry are extensive. And, Klasing et al. (23) have shown they may be immunologically mediated, probably arising from continual exposure of young birds to a wide variety of microorganisms and exacerbated by sub-optimal brooding conditions. We previously showed that cold stress-induced AGD can be significantly moderated in turkeys by probiotic treatment with $L$. reuteri (6). In the present report we have confirmed effectiveness of $L$. reuteri in moderating cold stress-induced AGD using another host species, the chicken. In addition, evidence is presented showing that $L$. reuteri is also effective in moderating AGD induced and/or exacerbated by other stressors such as peroral $S$. typhimurium challenge or exposure to a protein deficient diet. In another report (7), field trial evidence is presented showing that performance losses measured under actual commercial conditions can also be significantly moderated by probiotic treatment with $L$. reuteri.

A number of issues of biological and practical importance are raised by our findings. Inclusion of antibiotics in feeds to enhance productivity in the poultry industry is one such issue. Approximately 40 years ago it was discovered that certain antibiotics added to feeds at prophylactic concentrations (ca. $100 \mathrm{ppm}$ ) stimulated growth of chickens and turkeys, presumably by inhibiting growth and/or activities of certain GI tract microorganisms $(9,17,25,26)$. This growth-promoting effect was particularly evident when birds were brooded under sub-optimal environmental conditions and 
exposured to various stressors particularly those present during continuous production farming. Antibiotics are still widely used in the poultry industry today as growth promoters despite the fact that the practice is perceived a threat to public health by contributing to generation of antibiotic resistance factors which can be transferred to human pathogens $(9,17,35)$. It is possible, indeed likely, that their effectiveness may have declined or disappeared entirely in many commercial operations owing to gradual development and spread of resistance factors among the various microbiotic populations harbored within the gut ecosystem and in the liter environment $(18,29)$. Consequently, for the sake of both human health and animal production efficiency, there is widespread interest in use of probiotics as biological alternatives to prophylactic antibiotics (16).

Evidence that antibiotic and probiotic efficacies are functionally interrelated was presented in Table 1 (15, 34 ). It was seen that growth depression caused by a deficiency in dietary protein could be moderated by treatment with either $L$. reuteri or the antimicrobial regimen. This observation raises interesting questions concerning the role gastrointestinal microorganisms may play in the host's dietary nitrogen needs as well as in its overall health and well-being. Also, because the antimicrobial and probiotic treatments exhibited similar growth promotion, they may possibly share a common mode(s) of action (16).

Acknowledgments. The studies presented in this report were funded in part by the North Carolina Agricultural Research Experiment Station, the North Carolina Poultry Association, and the Southeastern Egg and Poultry Association. These studies were collaborative efforts also funded by BioGaia Biologics, Inc. (Raleigh, North Carolina, USA). BioGaia Biologics, Inc. owns the patent and proprietary rights to commercialization of the Lactobacillus reuteri-reuterin technologies. Mention of trade names in this report does not imply endorsement by the North Carolina State University or the North Carolina Agricultural Research Service, Raleigh, NC 27695 of the products named nor criticism of similar products not mentioned.

\section{REFERENCES}

(1) Axelsson LT, Chung TC, Dobrogosz WJ, Lindgren SE. 1989. Production of a broad spectrum antimicrobial substance by Lactobacillus reuteri. Microb Ecol Health Dis 2: 131-136.

(2) Barnes JH. 1993. Evaluating poult growth and productivity during brooding. Turkeys 41: 23-24.
(3) Barnes HJ. 1994. Poult growth depression costs industry big bucks. Turkey World, January issue: 12-14 .

(4) Barrow PA. 1992. Probiotics for chickens. In Probiotics: the Scientific Basis, Fuller R (ed), Chapman and Hall, London.

(5) Casas IA, Edens FW, Dobrogosz WJ, Parkhurst CR. 1993. Performance of GAIAfeed ${ }^{\circledR}$ and GAIAspray ${ }^{\circledR}$ : A Lactobacillus reuteri-based probiotic for poultry. Flair No. 6. 12. In Probiotics and Pathogenicity, Jensen JF, Hinton MH, Mulder RWAW (eds), DLO Centre for Poultry Research and Information Services, Spelderholt 9, 7361 DA Beekbergen, The Netherlands.

(6) Casas IA, Edens FW, Parkhurst CR, Dobrogosz WJ. 1998. Probiotic administrations of Lactobacillus reuteri moderate avian growth depression in turkeys. Bioscience Microflora 17: 125-131.

(7) Casas IA, Edens FW, Parkhurst CR, Dobrogosz WJ. 1998. Probiotic treatment with Lactobacillus reuteri protects commercial turkeys from avian growth depression. Bioscience Microflora 17: 141-147.

(8) Chung TC, Axelsson LT, Lindgren SE, Dobrogosz WJ. 1989. In vitro studies on reuterin synthesis by Lactobacillus reuteri. Microb Ecol Health Dis 2: 137-144.

(9) Coates ME, Dickinson CD, Harrison GF, Kon SK, Porter JWG, Cummins SH, Cuthbertson WFJ. 1952. A mode of action of antibiotics in chicken nutrition. J Sci Food Agric 1: 43-48.

(10) Dantzer R, Kelley KW. 1989. Stress and immunity: An integrated view of relationships between the brain and the immune system. Life Sci 44: 1995-2008.

(11) Dobrogosz WJ, Casas IA, Pagano GA, Talarico TL, Sjorberg B-M, Karlson M. 1989. Lactobacillus reuteri and the enteric microbiota. In The Regulatory and Protective Role of the Normal Microflora, Grubb R, Midtvedt T, Norin E (eds), Macmillian Ltd, London, p. 283-292.

(12) Dubos R, Schaedler RW. 1960. The effect of the intestinal flora on the growth rate of mice, and on their susceptibility to experimental infections. J Exp Med 111: 407-417.

(13) Dunham HJ, Williams C, Edens FW, Casas IA, Dobrogosz WJ. 1993. Lactobacillus reuteri immunomodulation of stressor-associated diseases in newly hatched chickens and turkeys. Poult Sci 72: 103 (Sup 1, Abst).

(14) El Boushy AR. 1990. What causes stress? Part 2 of the role of vitamin E. Poultry, Feb/March: 26-27.

(15) Fox SM. 1988. Probiotics: Intestinal inoculants for production animals. Vet Med, August: 806-830.

(16) Fuller R. 1992. Probiotics: The Scientific Basis, Chapman and Hall, New York.

(17) Hill DC, Branion HD, Slinger SJ, Anderson GW. 1952. Influence of environment on the growth response of chicks to penicillin. Poult Sci 32: 464-466.

(18) Human Health Risks Associated with Subtherapeutic Uses of Penicillin and Tetracyclines in Animal Feeds. 1988. Report of the Institute of Medicine, National Academy Press, Washington DC.

(19) Kandler O, Weiss N. 1986. Regular nonsporing Gram positive rods. In Bergeys Manual of Systematic Bacteriology, Sneath DHA, Mair NC, Sharpe ME, Holt JH (eds), Vol. 2, 
Williams and Wilkins, New York, p. 1208-1234.

(20) Kelley KW. 1985. Immunological consequences of changing environmental stimuli. In Animal Stress, Moberg GP (ed), American Physiol Soc Publ, Maryland.

(21) Kelley KW, Dantzer R. 1991. Growth hormone and prolactin as natural antagonists of glucocorticoids in immunoregulation. In Stress and Immunity, Plotnikoff NP, Murgo AJ, Faith RE, Wybran J (eds), CRC Press, Florida.

(22) Khansari DN, Murgo AJ, Faith RE. 1990. Effects of stress on the immune system. Immunol Today 11: 171-175.

(23) Klasing KC, Laurin DE, Peng RK, Fry DM. 1987. Immunologically mediated growth depression in chicks: Influence of feed intake, corticosterone and interleukin-1. J Nutr 117: 1629-1637.

(24) Lawrence TLJ (ed). 1980. Growth in Animals, Butterworths Publ, London.

(25) Libby DA, Schaible PJ. 1955. Observations on growth response to antibiotics and arsenic acids in poultry feeds. Science 121: 733-734.

(26) Lillie RJ, Sizemore JR, Bird HR. 1952. Environment and stimulation of growth of chickens by antibiotics. Poult Sci 32: $466-475$.

(27) Mitsuoka T. 1992. The human gastrointestinal tract. In The Lactic Acid Bacteria, Vol. 1. The Lactic Acid Bacteria in Health and Disease, Wood BJB (ed), Elsevier Applied Science, New York.

(28) Moberg GP (ed). 1985. Animal Stress, American Physiol Soc Publ, Maryland.

(29) Neu HC. 1992. The crisis in antibiotic resistance. Science 257: 1064-1072.

(30) Regnier JA, Kelley KW. 1981. Heat- and cold-stress suppresses in vivo and in vitro cellular immune responses of chickens. Am J Vet Res 42: 294-299.

(31) Sarra PG, Dellaglio F, Bottazzi V. 1985. Taxonomy of lactobacilli isolated from the alimentary tract of chickens. Syst Appl Microbiol 6: 86-89.
(32) Sarra PG, Vescovo M, Fulgoni M. 1986. Study on crop adhesion genetic determinant in Lactobacillus reuteri. Microbiologica 9: 279-285.

(33) Siegel HS. 1980. Physiological stress in birds. Bioscience 30: 529-534.

(34) Sissons JW. 1989. Potential of probiotic organisms to prevent diarrhoea and promote digestion in farm animals-a review. J Sci Food Agric 49: 1-13.

(35) Spika KS, Waterman SH, Soo Hoo GE, St Louis ME, Pacer RE, James SM, Bissett ML, Mayer LW, Chiu JW, Hall B, Greene K, Potter ME, Cohen ML, Blake PA. 1987. Chloramphenicol-resistant Salmonella newport traced through hamburger to dairy farms. New Engl J Med 316: 567-570.

(36) Talarico TL, Axelsson LT, Novotny J, Fiuzat M, Dobrogosz WJ. 1990. Utilization of glycerol as a hydrogen acceptor by Lactobacillus reuteri: Purification of 1,3-propanediol: NAD oxidoreductase. Appl Environ Microbiol 56: 943 948.

(37) Talarico TL, Casas IA, Chung TC, Dobrogosz WJ. 1988. Production and isolation of reuterin: a growth inhibitor produced by Lactobacillus reuteri. Antimicrob Agents Chemother 32: 1854-1858.

(38) Talarico TL, Dobrogosz WJ. 1989. Chemical characterization of an antimicrobial substance produced by Lactobacillus reuteri. Antimicrob Agents Chemother 33: 674-679.

(39) Talarico TL, Dobrogosz WJ. 1990. Purification and characterization of glycerol dehydratase from Lactobacillus reuteri. Appl Environ Microbiol 56: 1195-1197.

(40) Thaxton P. 1978. Influence of temperature on the immune response of birds. Poult Sci 57: 1430-1440.

(41) Ziprin RL, Corrier DE, Elissalde MH. 1989. Maturation of resistance to salmonellosis in newly hatched chicks: inhibition by cyclosporine. Poult Sci 68: 1637-1642.

(42) Zwilling BS. 1992. Stress affects disease outcomes. Am Soc Microbiol News 58: 23-25. 